\title{
Effectiveness of working memory on visual-spatial working memory performance of pre-school children with learning problem at risk
}

\author{
Farzaneh Bayat Shahbazi $^{1}$, Ali Akbar Arjmandnia ${ }^{2}$, Reyhaneh Nemati ${ }^{1}$ \\ 1-M.A, Department of Psychology and Education of Exceptional Children, University of Tehran, Tehran, Iran. \\ 2- Associate Professor, Department of Psychology and Education of Exceptional Children, University of Tehran, \\ Tehran, Iran (Corresponding Author). \\ E-mail: Arjmandnia@ut.ac.ir
}

Received: 03/10/2021

Accepted: 20/12/2021

\begin{abstract}
Introduction: Specific learning difficulties are the existence of disorder in one or more of the basic psychological processes which play a role in the process of understanding and using spoken or written language.

Aim: The current study aimed to investigate the effect of working memory intervention on visual-spatial working memory performance among the preschool children at risk of learning disabilities.

Method: This study was a quasi-experimental study including pretest and posttest design with a control group. The statistical population comprised all children who were studying in preschool centers and kindergartens (2016-2017) in Tehran (District 14). A sample of 20 preschool students who were selected through purposive sampling participated in this study. They were randomly divided into two experimental and control groups (10 participants in each group). The experimental group participated in working memory program to 60-minute 12 sessions during the three months. In order to measure the performance of working memory, the working memory subset of IQ scale, Tehran-Stanford-Binet test and N-Back test were used. The data were analyzed by SPSS-22 and t-Test.

Results: The mean and standard deviation of the subjects age are 6.2 and 0.45 , respectively. The results showed that the working memory intervention caused the improvement on visual-spatial working memory performance of children $(\mathrm{P}<0.001)$.

Conclusion: Considering the findings of the present study, it seems that visual-spatial working memory intervention can improve the working memory of preschool children and it can be used to enhance the visual-spatial working memory function of children and prevent the learning problems.
\end{abstract}

Keywords: Working memory, N-Back training, Learning problems

How to cite this article: Bayat Shahbazi F, Arjmandnia AA, Nemati R. Effectiveness of working memory on visual-spatial working memory performance of pre-school children with learning problem at risk. Shenakht Journal of Psychology and Psychiatry. 2022; 8 (6): 69-82 .URL: http://shenakht.muk.ac.ir/article-1-1286-en.pdf

Copyright (C) 2018 the Author (s). Published by Kurdistan University of Medical Sciences. This is an open access article distributed under the terms of the Creative Commons Attribution-Non Commercial License 4.0 (CCBY-NC), where it is permissible to download, share, remix, transform, and buildup the work provided it is properly cited. The work cannot be used commercially without permission from the journal. 


\title{
بررسى اثربخشى مداخله حافظه فعال بر عملكرد حافظه فعال ديدارى - فضايى كودكان يشدبستانى در معرض خطر مشكلات يادكيرى
}

\author{
فرزانه بيات شهبازى'، على اكبر ارجمند نيا'، ريحانه نعمتى' \\ ا. كارشناسى ارشد، گروه روانشناسى و آموزش كود كان استثنايى، دانشكاه تهران، تهران، ايران.

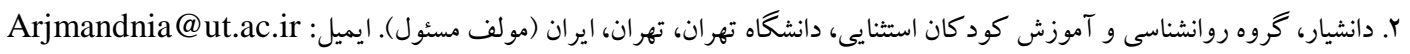

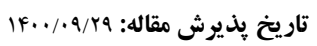

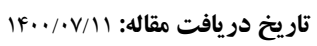

جكيده

مقدمه: مشكلات يادكيرى شامل وجود اختلال در يكك يا بيش از يكك فرايند روانشناختى پايه كه در روند دركك يا كاربرد زبان شفاهى يا نوشتارى نقش دارد، است. هدف: مطالعه حاضر با هدف تعيين اثربخشى مداخله حافظه فعال بر عملكرد حافظه فعال ديدارى- فضايى كودكان بيشدبستانى در معرض خطر مشكلات ياد گيرى انجام شد.

روش: يثوهش حاضر از نوع شبه آزمايشى با طرح بيشآزمون و بس آزمون همراه با كروه كنترل بود. جامعه آمارى شامل تمامى

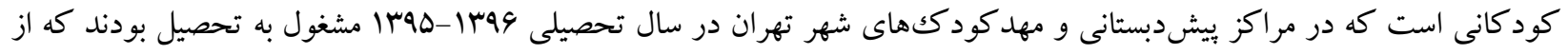

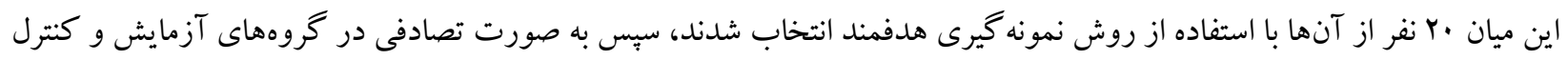

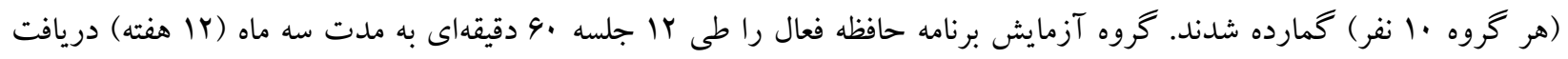
كردند. همجنين به منظور سنجش عملكرد حافظه فعال از خرده آزمون حافظه فعال مقياس هوش آزماى تهر ان-استنفورد-بينه و نرمافزار

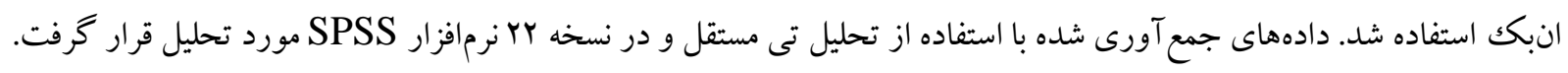

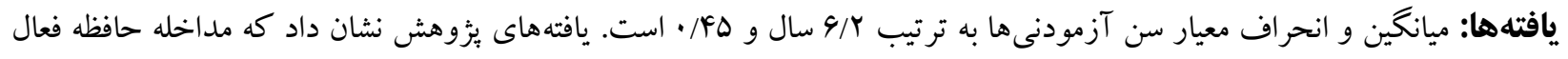

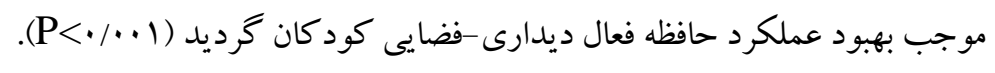
نتيجه كيرى: با توجه به نتايج يزوهش حاضر مىتوان نتيجه كرفت كه بازىهاى كامييوترى مىتوانند بر عملكرد حافظه فعال اثر

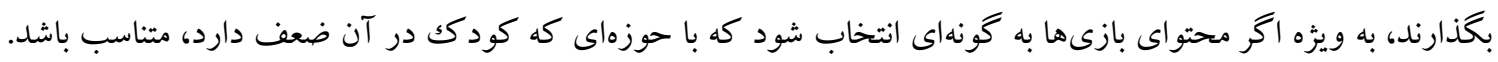
كليدوازهها: حافظه فعال ديدارى-فضايى، نرمافزار انبك،، مشكلات يادگيرى 
موضوعات عمو مى همجيون هنر استفاده مىشود. (افشارى

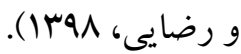
حافظه فعال را به عنوان ساختارى نظاممند كه باعث اتصال عملكردهاى حافظه كوتاه مدت و بلند مدت با ساير خرده

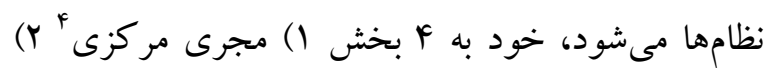

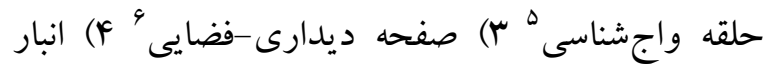

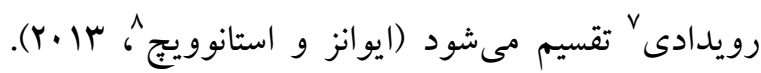

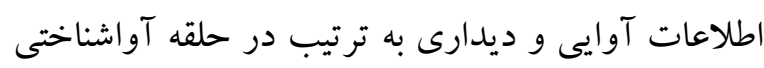

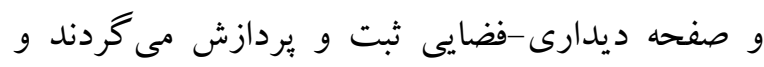

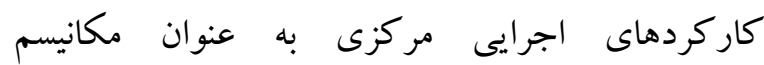
كنترل كننده نقش نظارتى بر اين خرده نظامها دارد. در واقع در اين مدل مهمترين مؤلفه، كاركردهاى اجرايى مركزى است. كاركردهاى اجرايى مركزى تعيين كننده

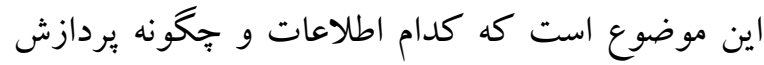
شوند. به طور كلى بردازشهايى نظير بازدارى اطلاعات

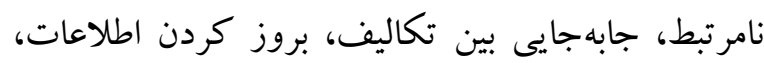
مديريت رفتار هدف و راهبردهاى بازيابى اطلاعات از حافظه بلندمدت توسط كاركردهاى اجرايى مركزى

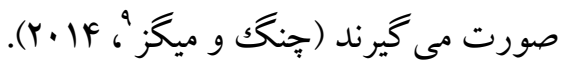

حافظه فعال شامل دو دسته مهارت كلامى و ديدارىفضايى است. دانشآموز از حافظه فعال كلامى استفاده مى كند تا دستور العملها را به خاطر آورد، زبان را ياد بحيرد و تكاليف مربوط به درك مطلب را اجرا كند. حافظه فعال ديدارى-فضايى براى يادآورى توالى ديدارى در رويدادها، الخوها، تصاوير و مهارتهاى رياضى مورد

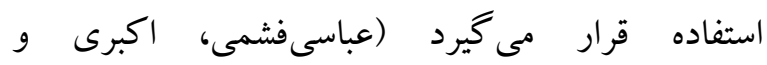

\footnotetext{
4- Central executive

5- Phonological lop

6. Visual spatial sketchpad

7- Episodic buffer

${ }^{8}$ - Evans \& Stanovich

${ }^{9}$ - Cheng \& Mix
}

مقدمه ناتوانى يادگيرى خاص ' عبارت است از وجود اختلال در يكك يا بيش از يكك فرايند روانشناختى بايه كه در فرايند دركك يا كاربرد زبان شفاهى يا نوشتارى نقش دارد

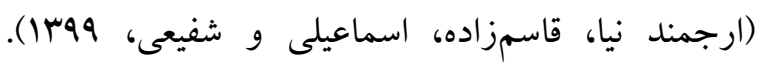
كود كان مبتلا به ناتوانى يادگيرى'، اصطلاح كلى است كه گروه ناهمخونى را تشكيل مىدهند، وجوه مشتركى كه در بين همه آنها وجود دارد اين است كه همخى در يادگيرى دروس مدرسه با مشكل مواجه مىشوند (هاشمى و عينى، . If I I مشخصه اصلى اين اختلالات در كودكك يا نوجوان عدم بيشرفت تحصيلى در زمينهى خواندن، بيان نوشتارى يا رياضيات در مقايسه با توانايى هوشى كلى كودكى است (اسماعيلى، شفا رودى، حسنى مهربان، برند، يزدانى و همكاران، هوسبا). موفقيت تحصيلى كود كان V ساله در رياضى و خو اندن و نوشتن انخليسى به موفقيت در تكاليف حافظه فعال مرتبط است (ولىنزادقناتى، بيرامى، فتحى آذر، واحدى و ميرنسب،

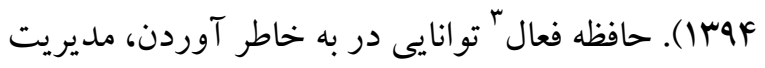
و بردازش اطلاعات است. در واقع از اطلاعاتى كه لازم است به خاطر آورده شود يادداشت ذهنى ايجاد مى گردد. حافظه فعال براى طيفى از فعاليتهاى آموزشى، از موضوعات بيجيده همجيون درك مطلب خو اندن، حساب و مشكلات مربوط به لغات گرفته تا تكاليف سادهاى جون رونويسى از تخته و جهتيابى، نقش اساسى دارد. حافظه فعال يكك مهارت شناختى يايه است كه براى

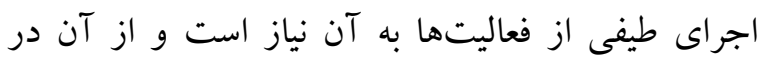
موضوعات اساسى درسى همجون خواندن، رياضيات و

\footnotetext{
1- Specific learning difficulties

2 - children with learning problem at risk

3. Working Memory
} 
يُؤهى فرا تحليلى آهنگر قربانى، حاجلو، سبهرى نسب و معزز (1) (1) نشان دادند تقويت حافظه فعال باعث بهبود عملكرد تحصيلى دانش آموزان با اختلال يادگيرى خاص مىشود. ساوير، انتفولكى، كارلسون، سالو و لاين (Y.IV) و فرا تحليل جند سطحى تمرينات انبكى لباعث بهبود عملكردهاى شناختى افراد مىشود. در مطالعهاى كه

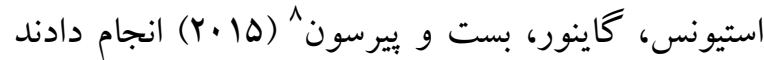
اثرات آموزش حافظه فعال بر بهبود عملكرد مغز نشان

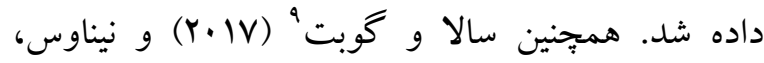

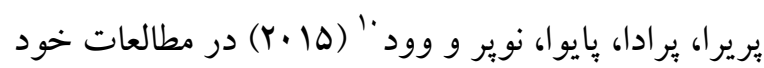
نشان دادند آموزش حافظه فعال با استفاده از بازى باعث تقويت عملكرد دانش آموزان در حال رشد در تكاليف آموزشى حافظه فعال شده است. با توجه به يزٔوهشهاى صورت گرفته مبنى بر عملكرد ضعيف حافظه فعال در كود كان داراى مشكلات ياد گيرى به نظر مىرسد تمرينات حافظه فعال باعث افزايش سرعت يردازش در حافظه فعال مىشود و نهايتاً بهبود مشكلات يادگيرى در اين كودكان را خواهد داشت. براساس مطالعه و بثزوهش محقق تاكنون در ايران، بثزوهشى اثر بخشى برنامه فعال بر روى حافظه فعال ديدارى-فضايى كود كان بيش دبستانى مورد بررسى قرار نداده است و در

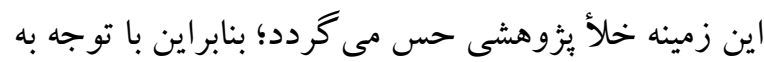
تأثير حافظه فعال ديدارى-فضايى در بيشرفت تحصيلى و ياد كيرى كود كان و دانش آموزان، هدف بثزوهش حاضر تعيين اثربخشى مداخله حافظه فعال بر عملكرد حافظه

6. Soveri, Antfolk, Karlsson, Salo \& Laine

7- N-back training

${ }^{8}$ - Stevens, Gaynor, Bessette \& Pearlson

${ }^{9}$ - Sala \& Gobet

${ }^{10}$ - Ninaus, Pereira, Stefitz, Prada, Paiva, Neuper \& Wood
حسين خانزاده، سنين F تا لا سال بهآرامى افزايش مىيابد (مهنگار و احمدى، 9411). كود كان با نقايص حافظه فعال مشكلاتى در هماهنگ همز همان بين ذخيرهسازى و بردازش دارند. آنها همجنين مشكلات بيشترى براى كنترل محر ككهاى

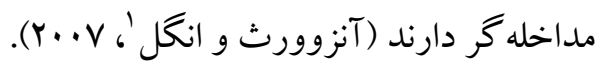
تمرين رايانهاى شناختى، شامل تكميل تمارين رايانهاى كوناگون مشخص شده براى بهبود عملكرد شناختى در

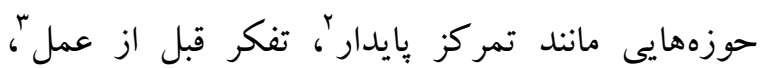
بردازش ديدارى و شنيدارى، خواندن و حافظه است كه در طيف گوناگونى از اختلالات شناختى مانند بيش فعالى همراه با نقص تمركز، اختلالات ياد گيرى، آسيب مغزى،

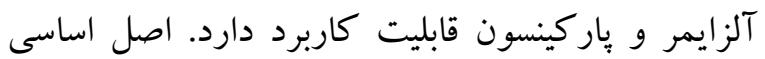
آن، كمكك به بهبود هسته توانايىهاى شناختى و ضرورت خود-كنترلى براى دست يابى به موفقيتهاى تحصيلى و شناختى است. برنامههاى رايانهاى تمرين شناختى با با بـ رويكردى فراشناختى و همافزا" و (اتمرين براى مهارتهئ"

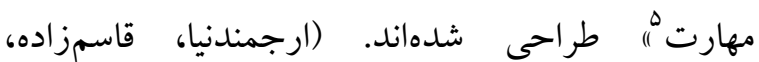

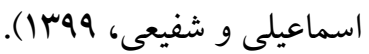
ناجى، شكوهى يكتا و حسن زاده (99 (I)؛ تيكدرى و

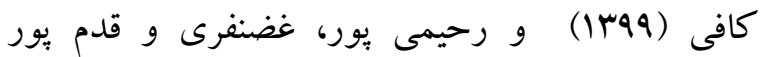
(941) در مطالعه خود نشان دادند آموزش راهبردهاى حافظه فعال بر عملكرد خواندن دانش آموزان نارساخوان مؤثر بوده است و باعث ارتقاى ظرفيت حافظه فعال كود كان مىشود. همجنين نتايج بزوهش حسنى، نادى و سجاديان (1\%99) نشان داد آموزش حافظه فعال بر بهبود مهارتهاى شناختى و فراشناختى كود كان مؤثر است. در

\footnotetext{
1. Unsworth \& Engle

${ }^{2}$ - Sustain Attention

${ }^{3}$ - Think before Act

4- Synergistic

5 - Drill for Skill
} 
كود كان استثنايى به صورت انفرادى اجرا گرديد. جهت با انخيزه كردن كودك و جذاب شدن برنامه آموزشى، هر جلسه را به ب بخش ·r دقيقهاى تقسيم كرده و در هر قسمت يكى از تمرينهاى تقويت حافظه فعال ديدارىفضايى ارائه شد. در هر جلسه، ·r دقيقه اول نرمافزار ان بك، ·r r دقيقه دوم بكيج بهسازى حافظه فعال و ·r دقيقه آخر نرمافزار آموزش و بهسازى توجه و حافظه فعال به آزمودنى ارائه مى شد. ملاككهاى ورود به يُزوهش شامل

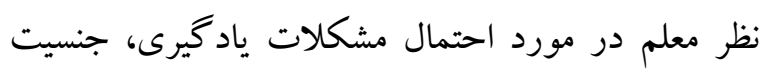
دختر و وِسر، رضايت از شركت در بزّوهش توسط و الدين و كودكك، محدوده سنى ه تا V سال و همجينين

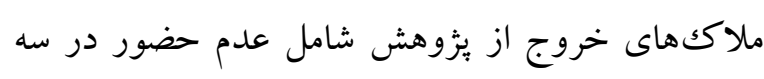
كلاس متوالى، كذر اندن برنامه يا بازىهاى مشابه و داشتن

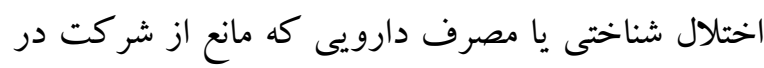

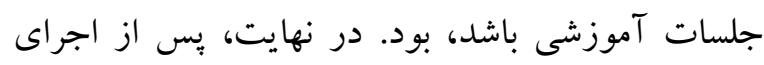
جلسات، شر كت كنند گان هر دو گروه آزمونهاى گرفته شده در مرحلهى بيش آزمون را مجدداً تكرار كردند.

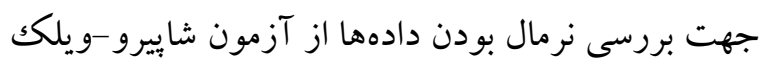
و آزمون كلمو گروف-اسميرنوف و براى بررسى اختلاف ميانگين نمرات دو گروه از آزمون تى مستقل استفاده شد. جهت تجزيه و تحليل دادهها از نرمافزار SPSS نسخه استفاده شد. باجلسه مداخله حافظه فعال ديدارىفضايى به صورت خلاصه در جدول ا توضيح داده شده است.
فعال ديدارى - فضايى كود كان بيش دبستانى در معرض خطر مشكلات ياد گيرى بود.

\section{روش} يثزوهش حاضر به روش شبه آزمايشى است با طرح ييش آزمون و يس آزمون همر اه با گروه كنترل انجام شد. جامعه آمارى يزٔوهش حاضر شامل تمامى كود كان مشغول به تحصيل در مراكز بيشدبستانى و و مهدكودككهاى شهر تهران (منطقه IF) در سال تحصيلى

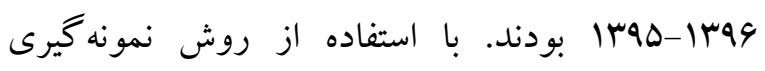
هدفمند، ابتدا براى تشخيص و انتخاب كودكان در بران

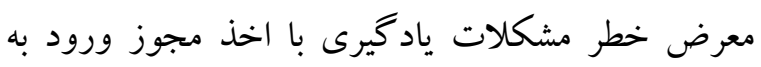

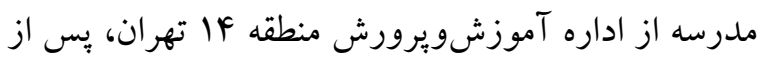
بررسى |l مدرسه و مهدكودك در ابتدا تعداد •r نفر دختر و يسر ه ساله در بايه بيشدبستانى كه توسط مربيان

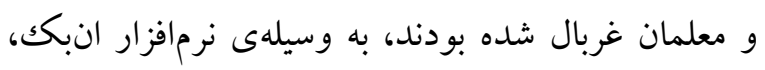

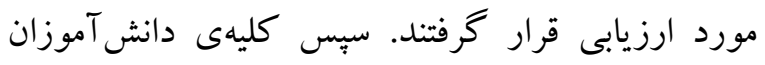
كروه نمونه به وسيلهى مقياس هوش آزماى تهراناستنفورد- بينه از نظر هوش مورد بررسى قرار گرفتند. به

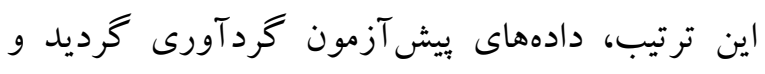
سִبس به روش تصادفى در گرووهاى آزمايش و كنترل

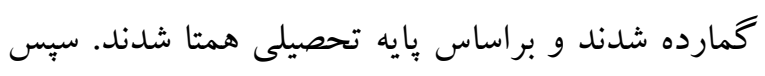
برنامهى مداخلهاى تقويت حافظه فعال بر روى گروه آزمايش طى با جلسه به مدت .4 دقيقه و به صورت هفتخى اجرا شد. برنامه مداخله در مركز مشاوره و خدمات روانشناختى صبا توسط كارشناس ارشد

جدول ا خلاصه جلسات مداخله حافظه فعال ديدارى فضايى

جلسه


تقويت حافظه فعال ديدارى فضايى و نرمافزار تمرينى انبك،، حافظه رو به جلو، بازى با كارت

دوم تا جهارم

تصاوير و حروف الفبا

هنجم تا هفتم تقويت حافظه فعال ديدارى فضايى و نرمافزار تمرينى انبك، حافظه معكوس، بازى با مكعبهاى

تقويت حافظه فعال ديدارى فضايى و نرمافزار تمرينى ان بكك، تثبيت حافظه، بازى باليو ليوان و مازها هشتم و نهم

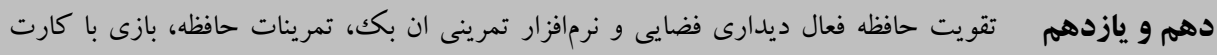

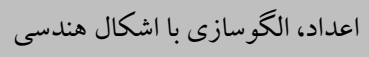

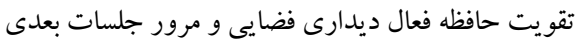

دوازدهم

برخوردار است. در تكليف انبكك مجموعه توالى از

محرككها به مراجع نشان داده مىشود. تكليف اين است

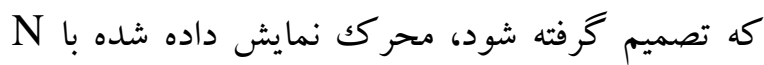

توالى قبل از خود، يكى است يا خير؟ به عنوان مثال 2

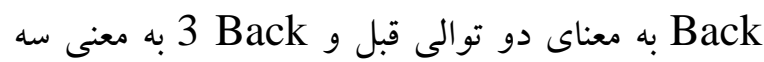
توالى قبل است. دشوارى تكليف با بالا بردن ميزان بيشتر مى شود و سرعت عمل و دقت آزمودنى با سختى روبرو مىشود. اعتبار اين آزمون در مطالعه فارسى با

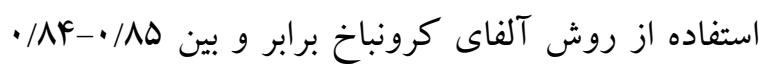

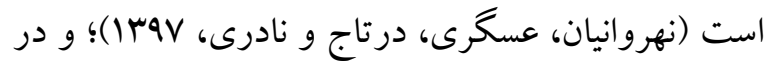
مطالعه جونز و ولاكو در سال ابr.r داراى آلفاى

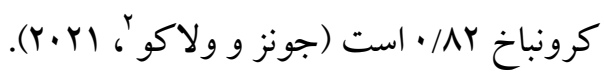

نرمافزار آموزث و بهسازى توجه و حافظه فعال!" تكليف تكليف آموزش و بهسازى حافظه فعال توسط موسسه روان تجهيز سينا طراحى شده است. تكاليف اين نرمافزار شامل حافظه رو به جلو، معكوس و تثبيت است. تكاليف فوق در دو نوع كلامى و ديدارى با اشكال، حروف الفبا و اعداد ارائه مىشود. با توجه به هدف يثوهش كه

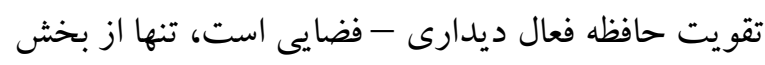
ديدارى نرمافزار استفاده شد. در اين تكليف در قسمت حافظه رو به جلو محر ككهاى ديدارى ارائه مىشود و بعد

2- Jones \& Vlachou

3- Working Memory Training
نرمافزار انبك: يكك تمرين براى تقويت حافظهى فعال

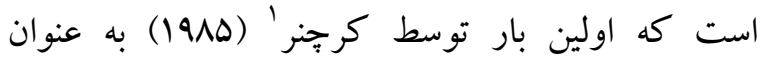
آزمونى براى ارزيابى حافظه ديدارى-فضايى معرفى شد. در اين برنامه كامييوترى به طور معمول مربعى آبى در يكك جدول ^ خانه به صورت تصادفى جند ثانيه نمايان شده و همزمان با آن يكك حرف از حروف الفبا به صورت شنيدارى بخش مىشود. تكليف آزمودنى اين است كه هر زمان هدف تصويرى قبلى را مشاهده كرده كليد A" A" در صورت شنيدن هدف شنيدارى قبلى كليد او در صورت ديدن و شنيدن هدف هاى قبلى به طور همزمان هر دو كليد مذكور را در صفحه كيبورد فشار دهد. در صورتى كه آزمودنى •ه درصد اهداف را به درستى به ياد آورد، نرمافزار به صورت خودكار سطح دشوارى تكاليف را بالا مىبرد. به اين صورت كه آزمودنى موظف است به ترتيب ا تا با محرك شنيدارى و ديدارى را به خاطر بسيارد. در صورتى كه آزمودنى به

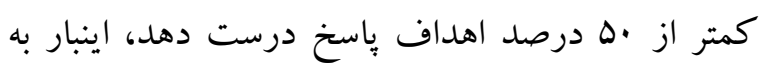
صورت خود كار به مرحله قبل باز گردانده مىشود. علت ارجحيت انبكك به ساير تكاليف حافظه فعال اين است كه اين تكليف از ييجيدگى كمترى نسبت به ساير تكاليف

\footnotetext{
1. Kirchner
} 
گرديد. اين نسخه به عنوان نسخه مطلوب در راستاى سنجش روانشناختى با تأكيد بر سازه هوش در دامنه سنى r تا •9 سالكى كاربرد داشته و از آن مىتوان در زمينهاى شناسايى، تشخيصى و گمارشى افراد در برنامهاى آموزشويرورش ويثه استفاده به عمل آورد. فرايند تفارق كذارى نيمرخ، به شناسايى دقيق عملكرد

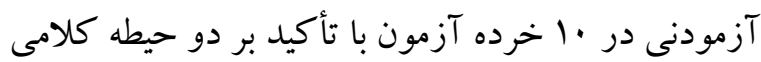
و غير كلامى معطوف بوده كه با توجه به ه عامل سازنده هوش، ·ل خرده آزمون را شامل مىشود. روايى اين

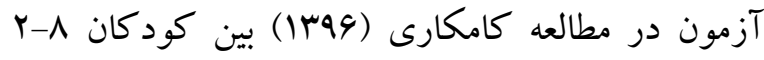

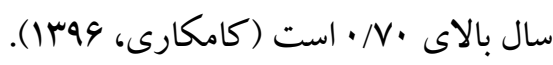
آزمون ديدارى فضايى انبك: در آزمونهاى انبكك مجموعه توالى از محرككها به آزمودنى نشان داده مىشود. اجراى اين تكليف بردازش هاى ذهنى مختلفى را به دنبال دارد: رمز گردانى محر ككهاى ارائه شده، مانيتور كردن، نخهدارى، نوسازى اطلاعات و همجينين تطبيق دادن محرك فعلى با N توالى قبل از خود است. تصميم گيرى، انتخاب، مهار و تحليل مداخله گرها نيز از جمله فرايندهاى شناختى است كه در مختلفى براى ارزيابى حافظه فعال وجود دارد. معروفترين اين

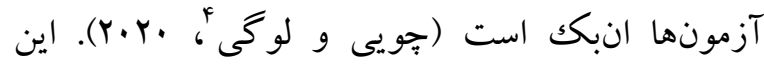

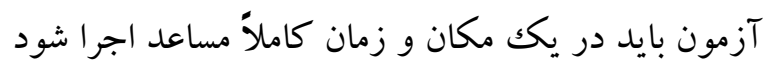
و شرايط اجراى آزمايش، از نظر روانسنجى رعايت شود. هدف اين است كه آزمودنى از حداكثر توانايى خود استفاده كند و در عين سرعت، بهترين عملكرد را داشته باشد. توصيه مىشود آزمايشخر قبل از شروع رسمى ستى

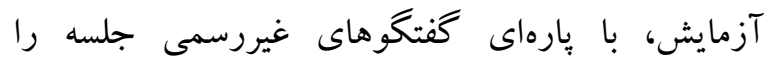
صميمى كند. لازم است قبل از اجراى آزمون از مهارت

4- Chooi \& Logie
از جند ثانيه از فرد خواسته مىشود به ترتيب ارائه محرككها جاى هر محركك را با موس علامت بزند. در قسمت معكوس به اين ترتيب است كه محر ككهاى ارائه شده را از آخر به اول علامت بزند. در قسمت تثبيت فرد بايد تنها جاى محرك ارائه شده را علامت بزند. بعد از

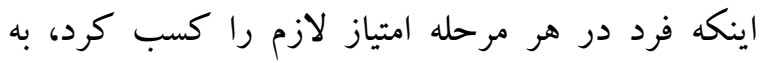
مرحله بالاتر با تعداد محر ككهاى بيشترى مىرود. اكر فرد در مرحلهاى امتياز لازم را به دست نياورد، دوباره به

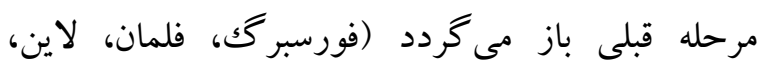

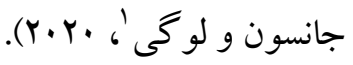
يكيج بهسازى حافظه فعال": بسته بهسازى حافظه فعال توسط قاسمى و همكاران در سال ^هץ| طراحى شده است كه تمرينات تقويت حافظه فعال را به صورت عملى

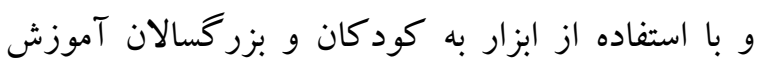
مىدهد. نتايج مطالعه قاسمى و همكاران نشان داد كه طراحى بسته توانبخشى شناختى خانواده محور موجب ارتقاى توجه يايدار دانش آموزان نارساخوان شده است. در اين بسته، تمرينات حافظه فعال ديدارى و كلامى ارائه شده است كه در بزوهش حاضر تنها از تكاليف ديدارى استفاده شده است. اين تمرينات با توجه به سن و ظرفيت حافظه افراد شروع مى شود و قبل از شروع تمرينات ابتدا بايد فراخناى حافظه را به دست آورد. تمرينات شامل تقويت مكانيابى، جهت يابى، ادراكك ديدارى و ساير

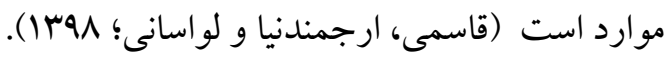
مقياس هوشآزماى تهران- استنفورد- بينه" : نسخهى نوين هوشآزماى تهران- استنفورد- بينه توسط افروز و

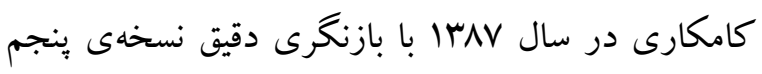
مقياسهاى هوشى استنفورد- بينه در سال ب..r، تدوين

\footnotetext{
1. Forsberg, Fellman, Laine, Johnson \& Logie RH

2 - Improving Working Memory Package

${ }^{3}$ - Tehran-Stanford-Binet Test IQ Scale
} 
فرد در استفاده از صفحه كليد رايانه اطمينان حاصل شود. يافتهها

نمونه مورد مطالعه شامل ·r كود كs ه تا V سال با ميانگين و انحراف معيار سن به ترتيب / 9/ و ها\&/، مشغول به تحصيل در مدارس بيش دبستانى بودند كه به صورت تصادفى در دو كروه آزمايش و كنترل گمارده شدند.

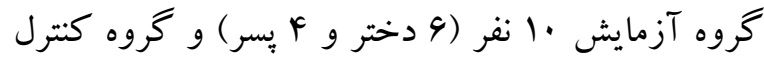

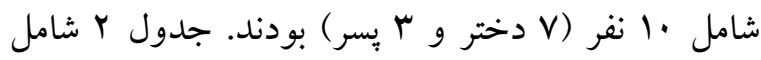
يافتهاى توصيفى آزمون حافظه فعال انبكك و خرده آزمون حافظه فعال تهران استنفورد- بينه به تفكيكك گرووه كنترل و آزمايش بدست آمده است. بس از ورود اطلاعات شخصى آزمودنى در قسمت مشخصات فردى، آزمون اجرا مىشود. قبل از اجراى آزمون اصلى، اجراى آزمايشى (مثال) خواهد بود. در آغاز قسمت آزمايشى و اصلى، توضيحات لازم روى صفحه نمايشگر ارائه مىشود (براى تفهيم تكليف توسط آزمودنى، در صورت لزوم، قسمت آزمايشى مىتواند جند بار تكرار شود) و آزمايشگ آزمودنى كاملاً تفهيم كند. با اعلام آمادكى آزمودنى، بارك، آزمون شروع مى شود (شهبازى و ارجمندنيا، . . IF).

جدول ب يافته هاى توصيفى آزمون حافظه فعال انبك و خرده آزمون حافظه فعال تهران استنفورد- بينه

\begin{tabular}{|c|c|c|c|c|c|}
\hline \multicolumn{6}{|c|}{ به تفكيك تروه كنترل و آزمايش } \\
\hline خطاى استاندارد ميانكين & انحر اف معيار & ميانكين & 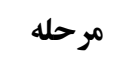 & 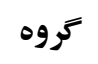 & ت ت \\
\hline $\mathrm{I} / \mathrm{VV}$ & $\Delta / \Delta q$ & $10 / v$ & بيش آزمون & \multirow{2}{*}{ آزمايش } & \multirow{4}{*}{ آزمون حافظه فعال } \\
\hline$r / 49$ & $\mathrm{~V} / \Lambda$ & $r q / 4$ & يس آزمون & & \\
\hline $1 / 49$ & $r / \cdot 1$ & $19 / 4$ & بيش آزمون & \multirow{2}{*}{ كنترل } & \\
\hline 1/09 & F/aF & 10 & يس آزمون & & \\
\hline$r / 9 F$ & $\mid r / F V$ & $Q Y / Y$ & بيش آزمون & \multirow{2}{*}{ آزمايش } & \multirow{4}{*}{ استنفورد بينه } \\
\hline$r / \wedge q$ & $|r / \pi|$ & 111 & 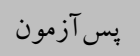 & & \\
\hline$r / r r$ & $V / \pi \Delta$ & $99 / 9$ & ي يش آزمون & \multirow{2}{*}{ 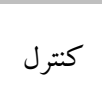 } & \\
\hline$r / r)$ & 9/99 & $9 \Delta / \Delta$ & يُس آزمون & & \\
\hline
\end{tabular}

I 4 I تفاوت قابل ملاحظهاى را در مقايسه با تفاوت ايجاد شده در گرووه آزمايش نشان نمىدهد. همجينين بيش فرضها بررسى شد و دادهها از توزيع نرمالى

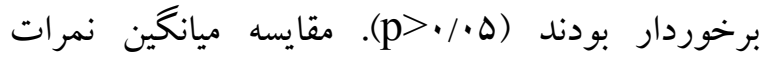
آزمون حافظه فعال انبكك و خرده آزمون حافظه فعال تهران استنفورد-بينه در دو گروه كنترل و آزمايش در جدول ب مورد ارزيابى قرار گرفته است.
همانطور كه در جدول r نشان داده شده است، در آزمونهاى حافظه فعال انبكك و استنفورد بينه، تغييرات قابل ملاحظهاى ايجاد شده است؛ به عبارتى ميانگين نمرات افراد گروه آزمايش قبل از مداخله به ترتيب برابر

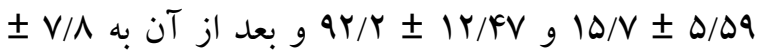

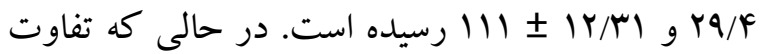

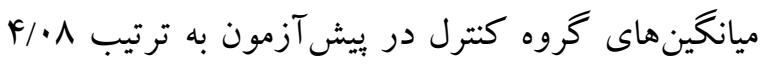

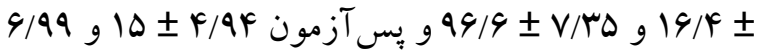


جدول r مقايسه ميانكين نمرات آزمون حافظه فعال انبك و خرده آزمون حافظه فعال تهران استنفورد- بينه

\begin{tabular}{|c|c|c|c|c|c|}
\hline معنى سطح & مقدار F & مقدار T & آزادى درجه & ميانكينها & تست \\
\hline$\cdot / \cdot \cdot 1$ & $19 / 1$ & $F / 91$ & 11 & $10 / 1$ & انبك \\
\hline .1 .04 & Q/Ar & $Q / Y \Lambda$ & 11 & $19 / 9$ & استنفورد-بينه \\
\hline
\end{tabular}

در واقع نتايج يزوهش هاى قبلى نشان داده است كه برنامه آموزشى حافظه فعال باعث بهبود عملكرد افراد در حافظه فعال ديدارى- فضايى و كلامى و همجينين بهبود مهارتهاى خواندن، نوشتن و رياضى مىشود. به طور

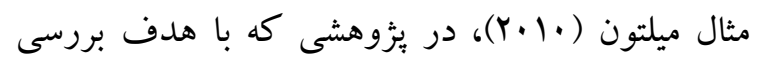
تأثيرات برنامهُ رايانهاى آموزش حافظه فعال بر روى توجه و حافظه فعال نوجوانان مبتلا به اختلال نقص توجه/ بيشفعالى و ناتوانىهاى ياد كيرى انجام شد، نشان داد كه

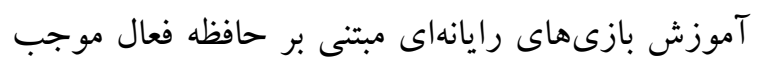

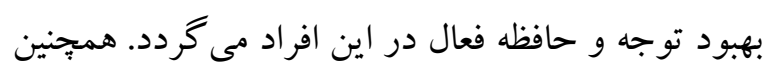

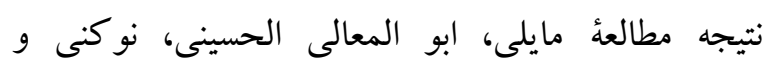

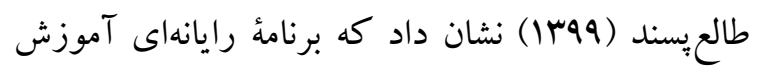
حافظه فعال باعث بهبود اين مؤلفه در اين كودكان مىشود، همجنين اين برنامة رايانهاى، بازدارى باسخ و

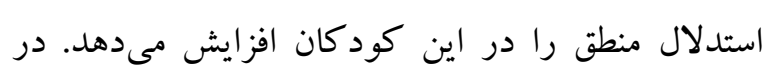
يزٔوهشى ديخر از هولمز و همكاران (Y. (Y)، مقايسهاى بر اثربخشى درمان دارويى و تمرين رايانهاى حافظه فعال بر روى كود كان با نارسايى توجه/بيش فعالى سنين 1 تا النجام دادند. آنها براساس يافتها جنين استدلال كردند كه درمان دارويى تنها موجب بهبودى عملكرد حافظه ديدارى فضايى گشته است؛ اما درمان تمرين رايانهاى حافظه فعال منجر به بهبودى در تمام اجزاى

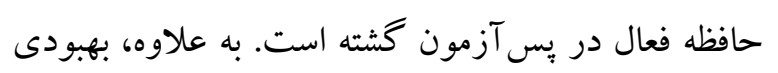

يافتها نشاندهنده تفاوت معنادار ميان نمرات بيش آزمون و يس آزمون در هر دو آزمون انبكك و حافظه فعال تهران استنفورد- بينه در گروه آزمايش نسبت به كرو دوره كنترل

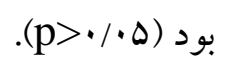

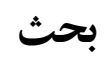

يُزوهش حاضر با هدف تعيين اثربخشى مداخله حافظه

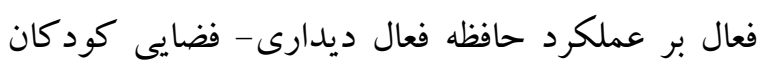
بيشدبستانى در معرض خطر مشكلات ياد كيرى انجام شد. نتايج بدست آمده نشان داد كه يس از بر بإ جلسه

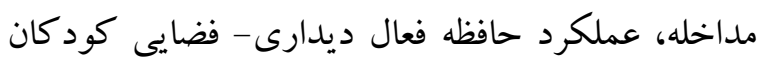
ييشدبستانى ارتقا و بهبود يافته است. اين يافته يزّوهش

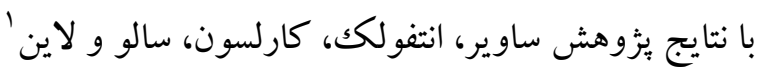

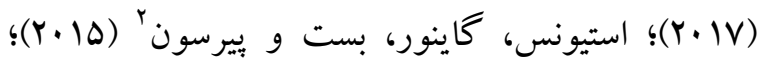

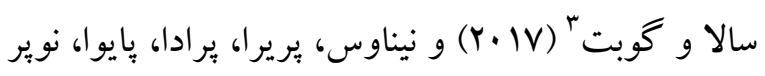

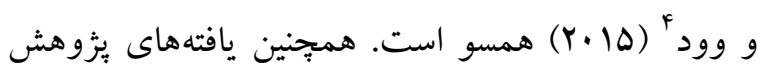
حاضر با نتايج بثوهش تيكدرى و كافى (99 (1)؛ حسنى،

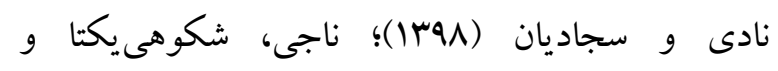

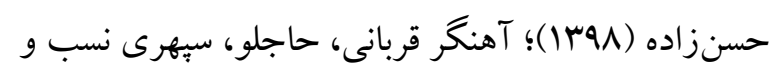

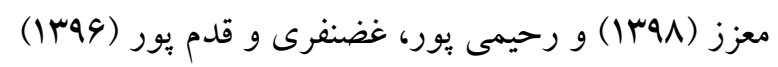
همسو است.

\footnotetext{
1- Soveri, Antfolk, Karlsson, Salo \& Laine

2-Stevens, Gaynor, Bessette \& Pearlson

3 - Sala \& Gobet

${ }^{4}$ - Ninaus, Pereira, Stefitz, Prada, Paiva, Neuper \& Wood
} 
است كه اين امكان را به دانش آموزان ناتوان يادكيرى مىدهد كه با تمرين و ممارست به طور همزمان حافظه شنيدارى و ديدارى خود را تقويت بخشيده و همجينين ميزان كنجايش حافظه را براى نخهدارى مؤلفهاى بيشتر

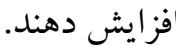

ولى نزاد قناتى، بيرامى، فتحى آذر، واحدى و ميرنسب

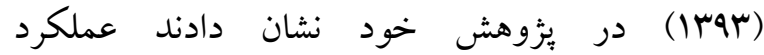
شر كت كنند كان در گروه آزمايش نسبت به دو گرووه ديخر در آزمون يادآورى مكعب نيز كه صفحه ديدارىفضايى را ارزيابى مى كند بهبود يافته است. اين نتيجه را مى توان جنين تبين كرد كه اين نوع مداخله با تأكيد بر اجرا كننده مركزى اثرات معنادارى در ساير حوزههاى حافظه فعال بخصوص صفحه ديدارى- فضايى داشته است. با توجه به اينكه در بُزوهش حاضر از نرمافزار انبك جهت توانبخشى حافظه فعال استفاده شده است، از اين رو نتايج با بززوهش فوق همسو است. نتايج يزوهش رادفر، نجاتى و فتح آبادى (هوس|) نشان داد مداخلات شناختى مبتنى بر بازىهاى توجهى بر ميزان كار آيى حافظه فعال و روانى كلامى دانش آموزان نارسا خوان مؤثر است. تقويت عوامل شناختى بايهاى همجِون توجه با استفاده از توانبخشى شناختى در سالهاى اول تحصيل مىتواند رويكرد مؤثرى در بهبود كاركردهاى اجرايى و درمان اختلال دانش آموزان نارساخوان باشد. همجنين نتايج بُزوهش حاضر با يُوهشى كه نجار زادگان، نجاتى، اميرى و شريفيان (Faf) انجام دادند همسو است. در بثزوهش فوق با استفاده از نرمافزار انبكك به توانبخشى شناختى كودكان با اختلال نقص توجه/ بيشفعالى يرداختند كه موجب بهبود حافظه فعال كود كان شده است؛ اما روى توجه تأثيرى نداشته است.
بدست آمده در تمام اجزاى به جز حافظه فعال كلامى تا 4 ماه بس از مداخله نيز باقى مانده است. قمرى گيوى و همكاران (اله||)، نيز در يُزوهشى نشان دادند كه بازى نرمافزارى بيشبرد شناختى بر بهبود بازدارى باسخ و حافظه فعال كود كان دجار نارساخوانى و نقص توجه / بيشفعالى تأثير دارد. ئزوهش ديخرى اثربخشى بازىهاى رايانهاى را بر افزايش حافظه فعال و كاهش نشانهاى اختلال رياضى نشان داده است (ارجمندنيا، شريفى و رستمى، سوس (). در بزّوهش ديخرى كه با هدف بررسى اثربخشى تمرين رايانهاى شناختى بر عملكرد حافظه فعال ديدارى فضايى دانش آموزان نارساخوان صورت كرفت، يافتها ها نشان داد كه دانشآموزان گروه آزمايش در نمره كلى آزمون حافظه فعال ديدارى - فضايى، نسبت به دانشآموزان كروه كنترل، عملكرد بهترى داشتند (شكوهى يكتا، لطفى، رستمى، ارجمندنيا، معتمد يخانه و

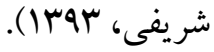
نتايج بثزوهش حاضر با يافتهاى آقاجانى، خانزاده و كافى

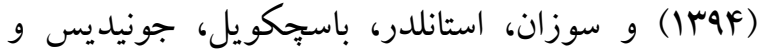

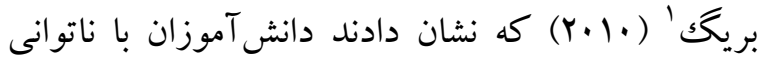
ياد گيرى عملكرد حافظهى فعالشان پِيين است، همسو است. در بزظوهشهاى فوق همانند يُزوهش حاضر، جهت بهبود عملكرد حافظه فعال از نرمافزار انبكك استفاده شده است و آقاجانى، خانزاده و كافى (Iraf) نشان دادند كار با نرمافزار انبك علاوه بر بهبود و افزايش ظرفيت حافظه فعال، اين مزيت را دارد كه زمينهاى ديخرى كه كود كان نارساخوان در آن مشكل دارند را تحت تأثير قرار دهد. نتايج برخى بئوهشها (شواليزر و همكاران، (Y. I) نشان داده كه اثربخشى نرمافزار انبكك به اين دليل

\footnotetext{
'- Susanne, Studer-Luethi, Buschkuehl, Jonides J \& Perrig
} 
اين مقاله مستخرج از بايان نامه در سال وهץ| در دانشگاه تهران به شماره ثبت آن بر روى افراد نمونه از سوى اداره آموزشويرورش

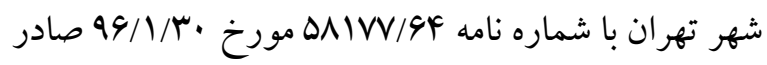
شده است كه معيارهاى اخلاقى آن زير نظر اساتيد راهنما

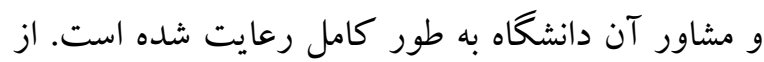
كليه كودكان، مربيان مهد و بيش دبستانى و مادران كود كان منطقه Fl If تهران كه نهايت همكارى و ممارست با اين بثزوهش را داشتند تشكر و قدردانى به عمل مى آيد. همجنين تمامى مراحل اجراى اين يُوهش در مركز مشاوره و خدمات روانشناختى صبا طى شده است؛ لذا مراتب قدردانى را از سركار خانم دكتر منيره كردلو، مديريت محترم كلينيك كه در يارى رساندن به ما از هيج كمكى دريغ نكردند، اعلام مىداريم.

\section{References}

Abbasi Fashami N, Akbari B, Hossein Khanzadeh AA. (2020). Comparison of the Effectiveness of Cognitive Rehabilitation and Neurofeedback on Improving the Executive Functions in Children with Dyslexia. J Child Ment Health. 7(2), 294-311. (In Persian)

Abedi A, Agha Babaie S. (2010). The Effectiveness of Working Memory Training on Improving the Academic Performance of Children with Dyscalculia. Joumal of Clinical Psychology. 2(4), 73-81. (In Persian)

Afshari A, Rezaei R. (2019). The effectiveness of Sand Smart software on executive functions (focused attention, the ability to organize and plan, and auditory and visual work memory) in students with dyslexia. Joumal of Leaming Disabilities. 8(3), 26-48. (In Persian)

Aghajani N, Hosseinkhanzadeh A, Kafi M. (2015). Effectiveness of N-Back training software on working memory in students with dyslexia.
همجنين برخى بثزوهش ها نشان دادند تو انبخشى شناختى و

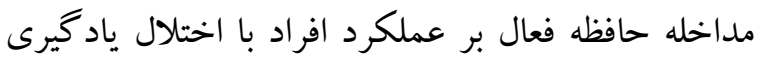
خواندن و رياضى تأثير مثتى داشته است (عابدى و

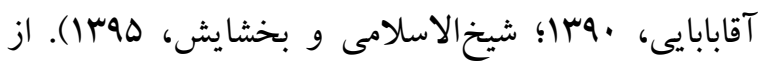
اين رو بثزوهش حاضر و يُزوهشهاى صورت گرفته نشان مىدهد كه بازىهاى كامييوترى مىتوانند بر عملكرد

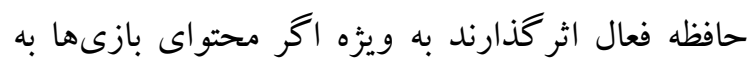
كونهاى انتخاب شود كه با حوزهاى كه كودكى در آن ضعف دارد، متناسب باشد.

\section{نتيجه كيرى} محققان با اجراى اين بثزوهش به اين نتيجه رسيدند كه بازىهاى كامييوترى مىتواند بر عملكرد حافظه فعال

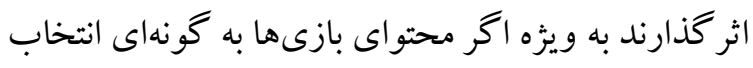
شود كه با حوزهاى كه كودكك در آن ضعف دارد، متناسب باشد و پِ از با با جلسه مداخله، عملكرد حافظه فعال ديدارى - فضايى كود كان بيش دبستانى ارتقا و بهبود يافته است. با وجود نهايت تلاش و دقت در امر اجرا؛ اما اين يخوهش با محدوديتهايى روبرو بود. از

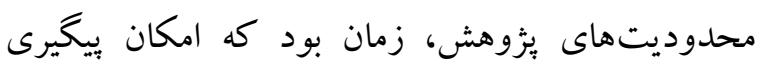
نتايج در آن ميسر نشد. ضمن اينكه دسترسى مجدد به برخى از اين آزمودنىها نيز امكانيذير نبود. از آنجا كه اين يُزوهش تنها در شهر تهران انجام يذيرفته است،

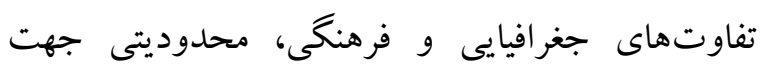

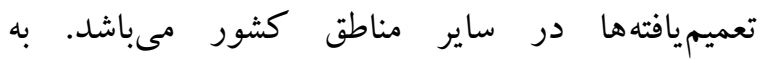
يثزوهشخران بيشنهاد مىشود اين مداخله را، براى ساير

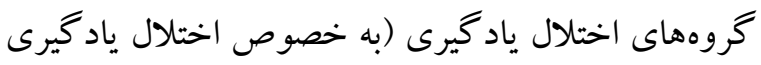

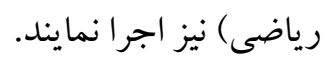


Journal of Leaming Disabilities. 4(3), 7-21. (In Persian)

Ahangar Ghorbani Z, Hajloo N, Sepehri Nasab Z, Moazez R. (2019). The effectiveness of working memory on academic performance of students with specific leaming disorder. A meta-analysis study. Joumal of Learning Disabilities. 8(4), 7-26. (In Persian)

Arjmandnia A, Sharifi A, Rostami R. (2014). The effectiveness of computerized cognitive training on the performance of visual-spatial working memory of students with mathematical problems. Journal of Leaming Disabilities. 3(4), 6-24. (In Persian)

Arjmandnia AA, Ghasemzadeh S, Esmaili F, Shafiee E. (2020). Effectiveness of visual-spatial working memory intervention on the performance of emotional working memory of student with mathematics disorders. Shenakht Journal of Psychology and Psychiatry. 7(5):145-155. (In Persian)

Bayat Shahbazi F, Arjmandnia A. (2021). The effect of visual-spatial working memory on mirror writing performance of pre-school children.Empowering Exceptional Children. Doi: 10.22034/ceciranj.2021.254648.1479. (In Persian)

Cheng YL, Mix KS. (2014). Spatial training improves children's mathematics ability. Journal of Cognition and Development, 15(1), 2-11.

Chooi WT, Logie R. (2020). Changes in error pattems during n-back training indicate reliance on subvocal rehearsal. Memory \& cognition. 48(8), 1484-1503.

Esmaili SK, Shafaroodi N, Mehraban AH, Parand A, Qorbani M, Yazdani F, Mahmoudpour A. (2016). Prevalence of psychiatric symptoms and mental health services in students with specific leaming disabilities in Tehran, Iran. International Joumal of Mental Health and Addiction. 14(4), 438-448. (In Persian)

Evans JSB, Stanovich KE. (2013). Dual-process theories of higher cognition: Advancing the debate. Perspectives on psychological science. 8(3), 223-241.
Forsberg A, Fellman D, Laine M, Johnson W, Logie RH. (2020). Strategy mediation in working memory training in younger and older adults. Quarterly Journal of Experimental Psychology. 73(8), 1206-1226.

Ghamari Givi H, Narimani M, Mahmoodi H. (2012). The effectiveness of cognitionpromoting software on executive functions, response inhibition and working memory of children with dyslexia and attention deficit/ hyperactivity disorders, Joumal of Leaming Disabilities. 1(2), 98. (InPersian)

Ghasemi S, Arjmandnia A, Gholamali Lavasani M. (2019). Designing family-based cognitive rehabilitation package and evaluating its effectiveness on executive functions of dyslexic students. Empowering Exceptional Children. 10(2), 200-215. (In Persian)

Hashemi Z, Einy S. (2021). The Effectiveness of Parent-Child Interactive Therapy on Parenting Stress and Parenting Self-efficacy of Mothers of Children with Leaming Disabilities. Journal of Learning Disabilities. 10(3), 125-142. (In Persian)

Hassani M, Nadi M, Sajjadian I. (2020). The Effect of the Cognitive-Emotional-Social Working Memory Training Package on the Improvement of Metacognition and Emotional Creativity in Students. J Child Ment Health. 7 (3):108-127. (In Persian)

Holmes J, Gathercole SE, Dunning DL. (2009). Adaptive training leads to sustained enhancement of poor working memory in children. Developmental science. 12, F9-F15.

Jones E, Vlachou S. (2021). Cannabidiol Does Not Cause Significant Changes to Working Memory Performance in the N-Back Task. Pharmaceuticals. 14(11), 1165.

Kamkari K, Afroz GhA, Davaei M, Shekarzadeh Sh. (2012). Practical guide to the new version of the Tehran-Stanford-Binet intelligence test. Tehran. Tehran University. (In Persian)

Kamkari K. (2017). Psychometric Properties of the New Version Intelligence Tehran- Stanford Binet in Learning Disabled 
Students. Psychometry. 6(22), 19-42. (In Persian)

Mahnegar F, Ahmaadi A. (2020). The Effect of Neuropsychological Rehabilitation on Visual Memory Performance and Social Adjustment in Children with Attention Deficit Hyperactivity Disorder. Qom Univ Med Sci J. 14 (3):1-9. (In Persian)

Mayeli M, Abolmaali Alhosseini K, Nokani M, Talepasand S. (2020). The Effect of Computer-based Cognitive Rehabilitation Therapy on Difficulties in Emotion-regulation among Students With Attention Deficit Hyperactivity Disorder. cmja. 10 (3):230-243. (In Persian)

Milton H. (2010). Effects of A Computerized Working Memory Training Program On Attention, Working Memory, and Academics, In Adolescents with Server ADHD/LD. Psychology Journal. 1(14), 120-122.

Nahravanian P, Askari P, Dartaj F, Bakhtyarpour S. (2018). The effect of cognitive education on working memory and focused attention of anxious children. 40 (12), 7-26. (In Persian)

Najarzadegan M, Nejati V, Amiri N, Sharifian M. (2015). Effect of cognitive rehabilitation on executive function (working memory and attention) in children with Attention Deficit Hyperactivity Disorder. The Scientific Joumal of Rehabilitation Medicine. 4(2), 97-108. (In Persian)

Naji E, Shokoohi-Yekta M, Hassanzadeh S. (2020). Effectiveness of Working Memory Educational Program on Phonological Working Memory and Phonemic Awareness in Dyslexic Students: A Neuropsychological Study. Neuropsychology. 5(19), 25-40. (In Persian)

Ninaus M, Pereira G, Stefitz R, Prada R, Paiva A, Neuper C, Wood G. (2015). Game elements improve performance in a working memorytraining task. Intemational journal of serious games. 2(1), 3-16.

Radfar F, Nejati V, Fathabadi J. (2016). The impact of cognitive rehabilitation on working memory and verbal fluency in dyslexic students (a single case study). Thoughts and Behavior in Clinical Psychology. 11(40), 17-26. (In Persian)

Rahimipour T, Ghazanfari F, Ghadampour E. (2018). The effectiveness of working memory strategies training on improvement of reading performance in dyslexic students. Knowledge \& Research in Applied Psychology. 18(4), 5261. (In Persian)

Sala G, Gobet F. (2017). Working memory training in typically developing children: A meta-analysis of the available evidence. Developmental Psychology. 53(4), 671.

Sheykholeslami A, Bakhshayesh A, Barzegar Bafrooei K, Moradi Ajami V. (2017). The Effectiveness of Working Memory Training on Reading Performance and Memory Capacity of Students with Reading Disability. Journal of Clinical Psychology. 9(2), 47-58. (In Persian)

Shiri Aminloo M, Kamkary K, Shokrzadeh S. (2013). The Concurrent validity of the new version of the Tehran-Stanford-Binet Intelligence Scale with the Wechsler Intelligence Scale for Children-Revised. J Except Educ. 7 (120):5061. (InPersian)

Shokoohi Yekta M, Lotfi S, Rostami R, Arjmandnia AA, Motamed Yeganeh N, Sharifi A. (2017). The effectiveness of computerized cognitive training on the working memory performance of children with dyslexia. Aud Vestib Res. 23(3):46-56. (In Persian)

Soveri A, Antfolk J, Karlsson L, Salo B, Laine M. (2017). Working memory training revisited: A multi-level meta-analysis of n-back training studies. Psychonomic bulletin \& review. 24(4), 1077-1096.

Stevens MC, Gaynor A, Bessette KL, Pearlson GD. (2016). A preliminary study of the effects of working memory training on brain function. Brain imaging and behavior. 10(2), 387-407.

Susanne MJ, Studer-Luethi B, Buschkuehl M, Jonides J, Perrig WJ. (2010). Relationship between nback performance and matrix reasoning- 
implications for training and transfer. Intelligence, 38, 625-635.

Tikderi A, Kafi H. (2020). Effect of Working Memory Training on the Improving Reading Performance and Working Memory Capacity in Children with Dyslexia. JPEN. 7 (1):50-61. (In Persian)

Unsworth N, Engle RW. (2007). The nature of individual differences in working memory capacity: active maintenance in primary memory and controlled search from secondary memory. Psychological review. 114(1), 104 .

Valinejadghanati Y, Birami M, Fathi AzarE, Vahedi S, Mimasab M. (2015). The Effectiveness of Strategy Training Based on Witt's Model in Improving the Working Memory and Math Performance of Students with Poor Working Memory. Journal of Psychological Achievements. 22(1), 89-110. (In Persian) 